Collaboration for the Common Good: An Examination of Challenges and Adjustment Processes in Multicultural Collaborations

Keywords: Teams, Collaboration, Cross-cultural 


\title{
Collaboration for the Common Good: An Examination of Challenges and Adjustment Processes in Multicultural Collaborations
}

\author{
Abstract \\ Multicultural collaborations are temporary, entities that are not embedded in a single organizational context, but \\ yet complete tasks such as building a house or making a film with the involvement of people from multiple \\ cultures. Although they share characteristics of multicultural teams, they lack many of the mechanisms that \\ teams embedded in organizations have at the ready to enable navigation of key challenges. Not much is known \\ about how they cope. Using an inductive approach, this study addresses four critical questions with respect to \\ multicultural collaborations. First, we sought to identify the most common challenges that multicultural \\ collaborations face. Second, we wanted to understand how multicultural collaborations react to those challenges. \\ Third, we examined the role of collaboration heterogeneity in the adjustment process. Finally, we wanted to \\ know whether adjustment facilitates collaboration performance. We examined these issues using comprehensive \\ field data from sixteen multicultural humanitarian home building collaborations that ranged in their degree of \\ cultural heterogeneity. Our analysis highlights many important aspects of multicultural collaborative work. First, \\ adjustment processes were critical in coping with their lack of organizational embeddedness. Second, \\ collaborations utilize a range of both internal and external strategies for adjusting. Third, when collaborations \\ experience challenges related to the way members work with each other, cultural differences may contribute to \\ the ability to make important adjustments. Finally, when significant challenges existed, adjustment processes \\ were related to performance in multicultural collaborations, yet over-adjustment was detrimental, suggesting the \\ importance of careful calibration of adjustment strategies to the magnitude and natures of challenges which exist. \\ Our findings have implications for theories of team processes and culture, as well as practical implications for \\ working across cultures.
}




\section{Collaboration for the Common Good: An Examination of Challenges and Adjustment Processes in Multicultural Collaborations}

A critical problem for organizational scholars of the twenty-first century is to begin to address the abundance of "organizing” that takes place outside the realm of conventional teams embedded in organizations. For example, each morning all over the world, retired men and women, parents and their teenage children, religious congregations, colleagues in the corporate world, college students, contracted builders and suppliers, city and government officials, and a host of other humanitarian-minded individuals come together in untested, unbalanced, and unexpected combinations to dig foundations, mix cement, construct walls, and eventually complete entire homes. Each of these endeavors frequently consists of individuals that run the gamut with respect to cultural origin, native language, age, experience, education, and occupational background. Nevertheless, these somewhat hodgepodge collaborative efforts have resulted in the completion of hundreds of thousands of homes, changing the lives of millions of people around the world. Similar sorts of collaborative efforts occur among actors, musicians, writers, and financiers for the production of a documentary film; and the integration of the skills and ideas of researchers, non-profit service providers, government agencies and volunteer educators to provide educational programs in developing remote communities. As much of this type of work occurs outside the boundaries of formal organizations and entails a much more fluid and permeable structure, many established organizational methods and routines available to organizationally embedded multicultural teams are nonexistent, hence magnifying and complicating the ability to cope with the new challenges that arise.

As a result, we shift the focus of prior inquiry from structured, stable teams that operate inside formal organizations to instead examine multicultural collaborations, defined as temporary, multicultural, organizationally unembedded entities organized for the purpose of pooling expertise, resources, information or social networks to create a specific product or service (Gibson \& Dibble, 2008). Two defining characteristics of multicultural collaborations include their often dynamic and highly diverse composition (e.g., they may include individuals from various functional backgrounds, organizations, and national cultures) and their complex and often volatile environments (e.g., they may be required to operate under severe time constraints, in rapidly changing environmental conditions, or among a constantly changing group of external stakeholders) (Gibson \& 
Dibble, 2008). While conventional organizations typically design teams of individuals that function together on an ongoing basis, collaborations are composed of collaborators with various organizational affiliations (or no organizational affiliation, because they are independent contractors or individual contributors) who converge for short periods of time and then disband. Inherent in this type of collaborative structure are challenges related to the potential for interpersonal conflict, a lack of shared understanding, loss of process knowledge and human resource shortages as collaborators engage and disengage. While conventional organizations house entire departments responsible for documenting challenges and implementing and routinizing solutions in knowledge management systems or online repositories, the more dynamic forms of collaboration we focus on here face the challenge of operating with limited resources to devote to organizational change. While traditional teams in organizations operate in conjunction with a fairly established, stable and re-occurring set of external stakeholders (e.g., long term clients, suppliers, community stakeholders, etc.), collaborations may face a new set of external stakeholders for each collaborative objective (e.g., each home building endeavor, each film project, each humanitarian relief effort), hence reducing the predictability of the external environment. In an organization context, there may be risk mitigation protocols, templates for project management, cycles of reporting on milestones, diagnostic tools, and perhaps even an organizational development staff to assist in identifying challenges, proactively managing them, and developing skills in responding and adjusting to them. These are unlikely to exist in a collaboration.

Prior research has highlighted a variety of change processes in collaborative entities. For example, the literature on role reconfiguration (Arrow \& McGrath, 1993), the use of negotiated role structures (Bechky, 2006), the incorporation of strategies to reduce miscommunication (Katz \& Te'eni, 2007), improvisation (Moorman \& Miner, 1998; Samra et al., 2008), bricolage (Baker \& Nelson, 2005), mutual adjustment (Zimmermann \& Sparrow, 2007), external activities (e.g., Ancona \& Cadwell, 1992), “x-teams” (Ancona, Bresman \& Kaeufer, 2002), and research on how environmental contingencies might require a particular leadership approach (Fiedler, 1964), all address ways in which members of teams might cope with change. However, much of this research has taken place inside an overarching organization, and recognizes the 
support that organizational embeddedness provides. So we are left to wonder, without such infrastructure, what stimuli might prompt changes, and how might multiculturalism play a role in responding to them?

In fact, some of the most interesting and perplexing challenges that collaborations currently face are related to the cultural complexity that often exists in collaborative structures. As Salas and Gelfand (2012, JOB special issue call for papers) note, “differences in culture and viewpoint can...lead to misunderstandings and interaction problems. Therefore, there is a pressing need to understand the processes and influences of intercultural collaboration and negotiation as well as how to manage the process to result in the most effective outcomes possible”. In multicultural collaborations, the challenges of cultural diversity are dramatically compounded by the lack of organizational embeddedness and the dynamism that accompanies it. Current theory and research has not addressed this important interaction in any substantial depth. We know very little about the process and emergent characteristics which might predict multicultural collaboration effectiveness, as they experience these unique challenges. For example, one common method of addressing cultural challenges is learning by doing and reflecting (Coultas et al. 2012), yet the fluid and temporary nature of collaborations may make it impossible to accumulate such learnings, and there is likely no organizational system or processes to facilitate it. Since the challenges inherent in multicultural collaborations are relevant to much of modern work (particularly with the expansion of globalization and virtual and electronic collaboration) and as these challenges are different from those experienced in more conventional team settings, there is a need to better understand the unique features that differentiate multicultural collaborations from other social aggregates, and the effective responses to their challenges.

To extend the boundaries of theory regarding team effectiveness, cultural diversity, and new collaborative forms, our research centers around the study of four critical questions regarding multicultural collaborations. First, we ask, what are the most common challenges that multicultural collaborations face? Second, we ask, in the absence of organizational systems, processes, and other resources, how do multicultural collaborations react to those challenges to adjust? Third, we investigate what is the role of collaboration heterogeneity in the adjustment process? Finally, we ask does adjustment facilitate collaboration performance? These are important questions which allow us to begin to construct a theory of 
multicultural collaboration, while also providing critical direction for collaborators engaged in this increasingly common form of organizing. We extend prior literature by examining challenges and adjustments in multicultural collaborations where there is often no prior history to draw upon, where there is no expectation of continuing work together (and hence reduced incentive to forge cohesive units), where there is no overarching organizational or functional loyalty, and where the collaboration may have so little information about their environment or the projected outcomes of their labor that they may not be able to proactively develop contingencies to avoid potential problems. Next, we describe the context, sample and procedures for a comprehensive field investigation of multicultural humanitarian home building collaborations in which we address the four critical questions. We then discuss our findings regarding these questions, concluding with the theoretical contributions and practical implications of our work and avenues for future research.

\section{METHODS}

As we currently know relatively little about adjustment processes in the context of collaborations, answering our research questions required an inductive approach that allowed for first hand observations of multiple collaborations in action. As pointed out in the recent literature, if we wish to study the dynamics of cross-cultural interactions and their effect on performance, rich and detailed descriptions of concrete actions in their real-life context are required which recover and preserve the meanings that actors ascribe to these actions and settings (Gephart, 2004; Gibson \& Vermeulen, 2003; Jackson et al., 2003; Vallaster, 2005;

Gibson \& McDaniel, 2011). The qualitative research methods we employed were non-standardized interviews, participant observation, and multiple case study analysis. These techniques have been viewed as particularly appropriate for cultural analysis (Gundry \& Rousseau, 1994), and have the advantage of grounding cultural analysis very much in concrete experiences based on specific events that have actually occurred in the collaborations. They also provide an understanding of the dynamics first within a single and subsequently, by comparison, between multiple collaboration settings (Eisenhardt, 1989).

\section{Context and Sample}


The context for the study is multicultural home building collaborations. These collaborations comprise individuals from a variety of cultures to help construct housing for people in need. Humanitarian home building projects are a useful context in which to examine our research questions because they are carried out in a wide variety of locations around the world, allowing us to examine multiculturalism and because they have features that are common to collaborations that take place in other contexts (e.g., the need for collaboration members to float on and off a project, the need to deliver a specific product in a pre-determined time period, and the necessity to interface with individuals and organizations outside the core collaboration in order to access needed information and resources). Collaborations in all of these contexts experience challenges related to their internal composition and their external interactions, and hence can benefit from the light this research sheds on such issues.

Sample. The sample for this study includes 16 multicultural home building collaborations: 4 in Costa Rica and 12 in Southern California. Participants in the home building collaborations ranged from approximately 8 to 50 individuals and included weekday retired volunteer crews, weekday corporate volunteer groups, weekend church group volunteers, and "brigades” of volunteers who came from another country to participate in home building projects alongside local participants, such as externally contracted construction supervisors, local volunteers, and home recipients. Many of the projects involved collaboration by individuals who spoke different languages and represented a variety of organizational, functional, socioeconomic, national, and cultural backgrounds. The duration of the home building process ranged from approximately 2 to 8 months. Collaborations in this study are operationalized as a set of participants that gathered together on a given day of work (or a few specific days of work in the case of the Costa Rican brigades) on a particular home building site. Because the work was primarily conducted by volunteers with varying levels of availability, each new day often saw a new set of participants, with only a few members potentially carrying over from one day to the next. Collaborations were composed fairly randomly, based on availability, although some effort was made by certain participants to “recruit” people with particular skills.

Data Collection Procedures. Semi-structured interviews were conducted with a humanitarian home building association that composed the collaborations, volunteer participants, and home recipients in order to collect 
information regarding challenges experienced, adjustment strategies, the extent to which external relationships were established and accessed, project goals and objectives, and outcomes. Interviewees were encouraged to talk openly about their experiences, which enabled the collection of subjective opinions, impressions and evaluations and of new and pervasive cognitions about the research topic, something that is much less possible in the more constraining framework of a systematic standardized questioning (Mayring, 2000). Interviews were digitally recorded, with all interviews that were conducted in Spanish being translated into English during the transcription process. All interviews were professionally transcribed.

Participant observation consisted of approximately 126 hours in the field observing and participating in humanitarian home building project teams. These observations resulted in approximately 143 pages of field notes and interview transcripts. Over the course of five months, a given site was observed at multiple points in time. Collaborations were sampled that were in a variety of stages of development (initial, middle, and final stages of building). During the observation process detailed notes were taken on demographic composition; core and peripheral subgroups; subgroup tasks; internal and external challenges experienced by the collaboration; role assignment and reassignment, revision of plans, and other types of adjustment; and an overall assessment of goal accomplishment and performance. The observation of the first few collaborations allowed us to begin to understand the challenges collaborations face and the kinds of adjustments they make as well as the relationships between internal and external challenges and internal and external adjustment (i.e., can collaborations internally and externally adjust to both internal and external challenges?). Further, these early visits allowed us to refine key definitional issues and shed light on new conceptual topics of interest (Strauss, 1987). Observation of the remaining collaborations allowed for further refinement of key emergent themes. Data gathering became increasingly focused on emerging themes as the study proceeded, a process referred to as theoretical sampling by Straus and Corbin (1998). Details for each of the collaborations observed, including the country in which it took place, the number of participants, the approximate number of hours collaborations were observed, and the stage(s) of the building process observed are included in Table 1.

Insert Table 1 Here 


\section{Analysis}

Collaboration summaries. In order to integrate our interview and observation data, we coded our interview data and examined the observations to determine correspondences. Interview findings and observations were discussed in numerous meetings among the researchers, leading to new insights. Detailed case studies were completed for each of the collaborations, helping us to cope early in the analysis process with the enormous volume of data.

First order coding. In the first stage of our coding, excerpts from field notes were assigned first order codes which captured nuances of the raw data (Strauss \& Corbin, 1998), including codes for cultural heterogeneity, external adjustment, internal adjustment, external challenges, internal challenges, and performance. The code for external adjustment represented any type of strategy a collaboration used to adjust to or deal with challenges, where the adjustment occurred by changing the way the collaboration interacted with individuals that were external to the collaboration, such as contractors, neighbors, government officials, or suppliers. The code for internal adjustment represented any type of strategy a collaboration used to adjust to or deal with challenges, where the adjustment occurred by changing the way the collaboration members worked with each other. The code for external challenges represented any type of challenge a collaboration experienced that originated in the collaboration's external environment. The code for internal challenges represented any type of challenge a collaboration experienced that originated in the collaboration's internal environment, meaning the challenge originated with the people in the collaboration. The code for cultural heterogeneity represented instances in which cultural differences were evident in observation (e.g., ethnic culture or national culture). The code for performance represented instances in which the extent to which the outcomes of the collaboration met the needs of stakeholders and constituents had been described or observed.

Second order coding. In a second stage of the analysis, we examined patterns and relationships among firstorder codes to assemble them into higher order themes, a process often referred to as axial coding (Straus \& Corbin, 1998). This second-order analysis allowed us to derive themes that might represent core concepts in an emerging grounded theory, drawing upon the insights of other qualitative analyses of change processes and dynamic contexts (Gioa \& Chittipeddi, 1991; Corely \& Gioia, 2004). After several iterations of comparing data 
and theory, we ultimately merged our findings and analyses into a tentative framework that we discuss below. For example, one set of themes denoted excerpts which indicated specific ways that collaborations adjusted.

Other second order themes captured relationships among first order codes, such as the relationship between internal challenges and types of adjustment, or between external challenges and types of adjustment, and between adjustment and performance. Finally, we identified two themes regarding how performance was experienced by members, one pertained to "task performance," the other pertained to "quality of experience.” For example, one member of the home building association concurred with this observation of the multi-faceted nature of performance for this type of collaboration, noting that "while house building is the mechanism we use, it is, as someone said years ago, actually a by-product of the work we do which is bringing people together for a common purpose, which in this case is house building." He agreed that the most important measure of a successful home building project is a combination of building a quality home on time and within budget, while creating a meaningful volunteer opportunity and building a sense of community in the area where the volunteers work. We discuss these themes and their implications below.

\section{FINDINGS}

In this section, we address each of our four research questions in turn, first discussing our findings with regard to the types of challenges experienced by the multicultural collaborations we observed. We then examine how the collaborations in our sample adjusted to the challenges they experienced. This is followed by our findings related to the role of collaboration heterogeneity (including cultural heterogeneity) in the adjustment process. Finally, we address our findings on the relationship between adjustment and performance. The relationships that were evident in our data are summarized in Figure 1, which depicts the roles of collaboration characteristics (lack of organizational embeddedness, heterogeneity), challenges, adjustment and performance that we observed in our research.

\section{What Are the Most Common Challenges Faced By Multicultural Collaborations?}

As noted above, one of the objectives of this study was to inductively derive categories which further delineate the variety of challenges collaborations may experience. In this research we addressed the variety 
of challenges that are pertinent and in some cases unique to multicultural collaborative forms of organizing. Our observations and interviews indicated that because of the dynamism, complexity, and uncertainty faced by collaborations, an important distinction is the locus of where challenges originate. Internal challenges originate inside the collaboration. They may include conflicts between collaboration members arising from different cultural perspectives, values or orientations, mishaps in coordination, or structural breakdowns. In our study, the need to socially integrate individuals joining a collaboration mid-project due to outside commitments, and the departure of critical information with the exit of a key collaborator were particularly unsettling. As members completed their individual components of the work and floated on or off, this dynamic composition resulted in a lack of a common knowledge repository and interpersonal difficulties as members must get to know one another.

In contrast, external challenges originate outside the immediate collaboration context. They may include challenges related to the physical settings in which the collaboration works; those related to the political, regulatory, economic or cultural contexts in which the collaboration is situated; those originating in key organizations with which the collaboration interacts; and those challenges related to the environmental contexts created by various member affiliations. Due to the fluid nature of participation in collaborations and the fact that collaborations are more permeable with their external environments, external challenges are more salient in the collaborations we observed than in those described in the literature on conventional, organizationally embedded teams. That is, in teams that exist within an organization, the firm often buffers them from the external environment, or at least attempts to reduce the uncertainty about the environment through their history of external relationships with suppliers, customers, other organizations, agencies, or governing bodies. For example, a multicultural team embedded in an organization likely draws upon the ongoing relationships the firm has with suppliers and customers to resolve dynamic challenges that arise in product delivery. But because collaborations are composed of individuals affiliated with a variety of external constituents with conflicting needs or interests, and given the lack of organization structures, resources, and scripts for dealing with external challenges (e.g., no in-house counsel, personnel policies, etc.), such challenges may be more difficult to detect and resolve. In fact, in collaborations, the lack of organizational 
embeddedness creates a premium on external adjustment, and multicultural collaborations may be a form of organizing particularly well suited to respond to external challenges and adjust.

\section{How Do Multicultural Collaborations React to Challenges?}

Next we examine ways in which collaborations adjust to respond to challenges in their internal and external environments. As anticipated, challenges often prompted the collaborations in our sample to make adjustments. Our observations indicate such adjustments can also be contrasted in terms of whether they are comprised of adjustments inside the collaboration (i.e., adjustments in the way members interact with each other) or outside the collaboration (i.e., adjustments in the way the collaboration interacts with outside stakeholders). Hence, a key finding is that collaboration challenges and adjustments can be conceptualized as a 2 x 2 dimensional configuration. Examples of the types of internal and external challenges that collaborations may experience, along with types of adjustment to these challenges, are provided in Table 2 . Note that we adopted labels for these quadrants that emerged during our observations and interviews.

Insert Table 2 Here

General Types of Adjustment. Internal adjustments were made among members of the collaboration in order to adjust to challenges related to internal processes and dynamics (e.g., adjustment through interaction among collaboration members to revise plans and schedules or resolve interpersonal conflict). We adopted the label "Housekeeping” for this quadrant in Table 2. As an example of Housekeeping, consider the following scenario involving a Latin Outskirts collaboration leader who was filling in for the assigned leader who happened to be in training, and who had left a great deal of slack for the substitute leader to pick up:

Alma said that the biggest challenge is being alone right now at this stage of the project. Hector is the one assigned to manage the project and the volunteers, but he is new, is in training and is not very detail-oriented according to Alma.

Additionally, we learned that internal adjustments may also entail changes made among members of the collaboration in response to challenges posed by the external environment (e.g., changing the task sequence of the collaboration's work in response to a delay in the delivery of key materials from external vendors). We 
determined that the external environment included all influences and factors that impact the collaboration but which are outside the boundaries of the collaboration. We adopted the label "Inventorying” for this quadrant, as depicted in Table 2, to highlight our observations regarding the need to “inventory” and utilize key internal resources in response to external challenges. As an example of Inventorying, our field notes include the following observation:

[The site supervisor] said, "Between you and me, I kept asking them 'Where are my tubs? Where are my tubs?” To which I asked, “So it was the vendors that sent them late?” Fred responded "Yeah, but we get them for free." Meanwhile the men were struggling to get the tub up the stairs. In order to get it to the stairs, Nate the plumber quickly pounded out part of the framing in the living room connected to electrical wiring while 5 guys tried to lift the huge tub unit up the stairs. They got it to the first landing. Someone then suggested "If you can lift it 2 stories, you can take the studs off up there”. After some more lifting and shifting of the tub, it finally made it up the stairs, followed by cheering and celebration. Nate commented, “Fred and I had a bet whether we could get that up here. Man, you don't know what a beautiful sight that is."

Collaboration external adjustment entails adjustments made by members of a collaboration by changing the way they interact with individuals or organizations external to the collaboration (e.g., government leaders, regulatory agencies, technology experts, external business leaders). Although the change itself is externally focused, such changes were sometimes made in order to adjust to challenges that originated inside the collaboration (e.g., contracting with local workers to adjust to internal skill deficiencies). We adopted the label “Contracting” for this type of adjustment in Table 2. As an example of Contracting, one Inner City participant described a scenario where contractors were engaged to provide a valuable roofing skill that had caused a great deal of extra stress for the volunteers and their leader:

Kelly looked out the back and mentioned to Shauna and me that it looked like the contractors were doing the same thing they'd done on the roof on the front house, only they 
look like they know what they're doing. They're putting up beams and the roof rafters today. Kelly remarked "if they get it right the first time, it will be worth the money." When they did this work on the front house "it was a pain!"

External adjustment may also involve adjustments made by members of a collaboration vís a vís their external constituents in response to challenges arising in their external environment (e.g., re-negotiation of schedules with contract workers due to delays imposed by local authorities). We adopted the label "Liaising" for this type of adjustment in Table 2. As an example of Liaising, our field notes include the following observation about an external challenge that resulted in the Coastal collaboration needing to bring in contract workers earlier than they had anticipated to complete utility and road work:

The fire department shut down their work on the house across from where we're working this morning. The four units (the ones that are shut down) look like they're partially framed, they don't have roofs, and they have blue tarps draped over them now. They said that the fire department made them stop working on those units because they weren't in compliance with the fire code...the regulation says that there has to be a fire hydrant within 150 feet of each house and they didn't have one close enough to these 4 units. They haven't installed fire hydrants in the development yet. I asked how this sequence of events would play out ideally. The other volunteer told me that they didn't have the funding to put the utilities in at the beginning.

Further, analyzing the field notes for the frequency data of each type of adjustment/challenge combination we found that the vast majority of adjustments made were internal adjustments, regardless of locus of the challenge or reason for the adjustment. Observation data indicated that internal adjustment to external challenges is the most frequent adjustment/challenge combination, with 59 (52\%) of the adjustments to challenges that we observed being "Inventorying” adjustments; 36 (32\%) of the adjustments to challenges that we observed being "Housekeeping” adjustments; 14 (12\%) of the adjustments to challenges that we observed being "Liasing” adjustments, and 4 (4\%) of the adjustments to challenges that we observed being “Contracting” adjustments. This makes sense given collaborations (and also teams) often have more control over internal processes than external processes. However, prior research has documented how vital external 
activities are, particularly in dynamic and uncertain environments (Ancona et al., 2002; Ancona \& Bresman, 2007; Gibson \& Dibble, 2012). As we discuss later, collaborations that did make external adjustments to external challenges often experienced enhanced performance, and we would argue this is particularly true when the collaborative effort lacks organizational embeddedness, because their external adjustment serves as a substitute for the organizational resources and processes that might otherwise buffer them from the environment. Taken together, these findings are important because they allow us to begin to understand the variety of ways in which collaboration adjustment takes place, as well as the types of internal and external factors that trigger the need for these adjustments. This is a critical first step to a more in-depth examination of the ways in which different types of adjustment may impact collaboration performance.

Specific Strategies for Adjustment. Beyond identifying the general types of adjustment that collaborations utilize to respond to challenges originating in both their internal and external environments, we observed a continuum of specific adjustment responses on both the internal and external dimensions, ranging from major adjustments (high effort and more substantial modification) to minor adjustments (e.g., low effort and minor modification), a notion suggested by Gibson and Dibble (2008), but not yet documented empirically. Specifically, we observed four key themes, each capturing an adjustment strategy: retreating, resolving, reconfiguring, or re-structuring. Internal and external examples of each appeared in the data (see Table 3). When collaborations "retreated", they tended to at least temporarily ignore rather than attempt to immediately address a challenge. In these cases, sometimes there was no immediate solution or the challenge could be at least temporarily overlooked. An example of this was experienced by collaborators who worked on the Latin Outskirts site. Due to an unexpected problem related to transferring critical funds, the local leader was not able to be with the collaboration participants when they arrived in Latin America to begin their collaborative endeavor. In response to this challenge, collaboration members opted to just wait and delay the start of their work. Another example of "retreating” was provided by a Canadian collaboration working on the Latin City 2 collaboration. During their preparation for their work together, the Canadian dollar weakened against the American dollar (the currency in which all expenses had to be paid) and money was lost. There was little that the collaboration could do to respond to this, and they ended up simply having to pay more than they otherwise would have. A third 
example of "retreating" occurred on the Coastal 2 collaboration. Here, a number of collaboration members needed to talk with the construction lead on the site in order to receive direction on individual projects. Their adjustment to the challenge of not having adequate information or resources from which they could seek this information consisted of simply waiting their turn. While "retreating” carries the connotation of drawing back, recoiling, or moving away from something, we use this term here to indicate a choice to relinquish attempts at adjustment. At times, "retreating” was a result of not making any alteration at all (as in the Latin City 2 example). At other times it was a conscious decision to wait for help (as in the Latin Outskirts and Coastal 2 examples). In these instances there is often either nothing that collaboration members can do or they feel that a better resolution will come by waiting for assistance.

Insert Table 3 Here

Representing greater effort and modification, “resolving” often involved negotiating with internal or external stakeholders, or working together to solve a problem or respond to an opportunity. In these cases, a fairly simple adjustment or resolution was sufficient. One example of this was the discovery by collaboration members on the Coastal 2 collaboration that moving sandbags across the lot (which consumed time and required considerable physical effort) could be accomplished by borrowing a backhoe from the contractors to transport the sandbags across the lot, loading the bags into a wheelbarrow, and then distributing the bags along the fence line as required. Another example of “resolving” was the Latin Outskirts participants’ use of a translator to enable communication between collaboration participants and external contacts such as their driver, a store clerk, and the contracted construction lead.

Representing still greater effort and modification, “reconfiguring” involved changing roles or sub-group compositions within the collaboration. In the cases where adjustment involved reconfiguration, some collaborations re-arranged tasks, and in others collaborators took on additional tasks to compensate for missing collaboration members. In other cases, reconfiguration entailed bringing in external resources to compensate for a skill set that was lacking internally. An example of "reconfiguration" involving internal collaborators was a Latin American country volunteer coordinator taking on additional roles to compensate 
for the absence of the project volunteer coordinator who was attending training in another city. While this adjustment entailed a significant addition to the country volunteer coordinator's responsibilities, this reconfiguration did little to change the structure of the collaboration and involved making adjustments that impacted very few individuals. An example of reconfiguration which involved the incorporation of external collaborators and subsequently the reconfiguration of collaboration members was the incorporation of one of the contractor's men to help dig a septic tank pit requiring significant physical strength and endurance on the Latin Outskirts site. Subsequently, collaboration participants were able to redistribute their labor to other tasks better suited to their abilities and levels of physical endurance.

Finally, the incorporation of the fourth type of adjustment strategy_- “re-structuring”-recognizes that at some point a new strategy or structure may be needed. Some examples of this became apparent during our field observations and interviews. One example of this was a particular branch of the home building association which was designed to involve musicians and other professional artists in domestic and international home building collaborations which re-organized under a regional affiliate, rather than remaining a part of the broader international home building association’s direction. This adjustment was made in order to make participation in these collaborations as simple as possible for the artists involved. Another example of re-structuring was described for us by a board member of one of the home building association's affiliates. He noted that the home building association had revamped their strategy in recent years to purchase repossessed homes and refurbish them rather than building all of their homes from scratch. As re-structuring is a more macro level adjustment strategy, this approach may be more commonly witnessed in groups of collaborations or across multiple collaborative endeavors.

As noted in Table 3, we observed 23 instances of retreating, 136 instances of resolving, 27 instances of reconfiguring, and 1 instance of re-strategizing/re-structuring in this sample. Hence, the resolving strategy, which required modest effort and modification (i.e., at the midpoint on a continuum) was by far the most frequently employed. As we report below, this is likely an effective strategy, resulting in higher performance than would strategies that entail less or more substantial modifications, because it protects the multicultural collaboration from the risk of "over adjustment.” Interestingly, we noted that the collaborations that we 
identified as being moderately high or high on cultural heterogeneity were generally above average in their use of "resolving” strategies. We also noted that the collaboration that we identified as the lowest on cultural heterogeneity made least use of "resolving” strategies. Hence, it is possible that selection of midrange adjustment strategies is a strength of collaborations that are high in cultural heterogeneity.

Adjustment to Cultural Challenges. We identified a particular theme regarding both internal and external challenges that pertained to culture, that is, when the content of the challenge was cultural. An example of an internal cultural challenge was the cultural inclination of American collaboration members to work hard in the rain despite the potential danger, resulting in the need for leaders to encourage them to slow down or stop to keep people safe; that is, adapt cultural propensities to the nature of the situation. An example of an external cultural challenge was the need for using translators and sign language to communicate between the contracted construction supervisors and collaboration members.

In our study, cultural challenges were among the most difficult challenges collaborations faced. In fact, the cultural challenges in our sample were often issues to which collaborations did not adjust or to which adjustments were less effective. For example, it is often expected that recipient families are involved in the building process (e.g., “sweat equity”). However, this was not always the case in Costa Rica. The Latin Outskirts collaboration never really dealt with the issue that the recipient families did not get involved in the building process. It was not until a much later interview with Silvia, the mother of one of the recipient families, that we learned that in Latin America there is a cultural taboo against women working in construction. Additionally, on the Rainforest collaboration there were judgments and attributions made about the behavior of individuals involved in a challenge related to the timing of a meal provided by Latin American collaborators. This challenge appears to have been related to mismatched, culturally influenced, objectives. While the Latin American participants were working to create a high quality meal at the expense of lost working hours, the American participants were frustrated with the delay. Unfortunately, neither party got to the heart of these cultural issues in order to effectively resolve them, and this appeared to negatively affect collaboration performance (particularly with regard to the "quality of experience" element of performance). It is possible that these challenges were not adequately addressed because collaborators felt inadequately prepared to deal with the cultural challenges related 
to their work. Another possibility is that collaborators may have viewed cultural challenges as related to some unchangeable aspect of those with whom they worked, hence opting to deal with these challenges by "retreating” rather than selecting a more effortful and effective means of adjustment (such as “resolving”).

Shifts in Leadership for Cultural Challenges. A related theme that emerged pertained to a specific type of internal adjustment involving reconfiguration that the multicultural teams in our sample employed -- shifts in leadership roles. Recent research suggests a relationship between shifting leadership and team performance (e.g., Avolio, Jung, \& Sivasubramaniam, 1996; Ensley, Hmieleski, \& Pearce, 2006; Klein et al., 2006). Our observations extend this research by providing evidence that as a mid-range type of adjustment strategy (i.e., relatively modest effort and modification) shifts in leadership may be particularly beneficial means of adjusting to cultural challenges.

That is, while cultural challenges appear to be among the most difficult variety of challenges to respond to, we found examples in our study in which a shift in leadership was an effective means of responding to cultural differences. For example, Vic, one of Latin City's formal leaders, noted that those people he thought would come up as leaders had not, but others that he did not expect had started to be leaders. In this case, Josh and Jared had emerged as informal leaders in the collaboration. This probably had a lot to do with the fact that these two could communicate with Spanish speaking formal leaders and the construction foreman, as well as collaboration members. This made them critical to the collaboration's communication processes and these emerging informal leaders were always in the know. In contrast, Debra, one of the formally designated leaders, lacked the ability to communicate across the cultural sub-groups and didn’t seem to take as much of a leadership role.

\section{What is the Role of Collaboration Heterogeneity in the Adjustment Process?}

The equivocal relationship between heterogeneity and performance has been highlighted by numerous scholars (e.g., Schippers et al. 2003; Gibson \& Vermeulen, 2003). Empirical evidence shows heterogeneity can be an impetus for consideration of a wider range of perspectives with a positive effect on performance (e.g., Hoffman \& Maier, 1961; Watson, Kumar \& Michaelson, 1993), as well as a potential source of dissatisfaction and turnover (e.g., Jackson et al., 1991; Wagner, Pfeffer, \& O’Reilly, 1984). Schippers et al. (2003) noted that 
"most research has examined the direct impact of diversity on team process and team outcomes, neglecting the role of the situation” (Schippers et al., 2003: 780). Subsequently, recent research has begun to explore the role of moderators in the relationship between heterogeneity and outcomes.

Our study provides us with some evidence that when faced with considerable challenges (a moderator of the relationship between heterogeneity and adjustment), collaborative cultural heterogeneity may allow collaborations to better internally adjust to both internal and external challenges. For example, Inner City 2 was one of the most heterogeneous collaborations that we observed, with a variety of ethnicities (including AfricanAmericans, Latinos, Asians, and Caucasians), a fairly wide range of ages (from approximately mid-20’s to mid60’s), participants from a variety of functional backgrounds, both Spanish and English-speakers, and a mix of male and female participants. This collaboration also experienced high levels of internal challenges including the trial of trying to match participants to tasks in which they were willing and able to engage, volunteer errors that resulted from lack of construction experience, and a language barrier between the participant who spoke only Spanish and the site leader. Perhaps because of the variety of skills and experience levels collectively held by this collaboration, its members were capable of engaging in a great deal of internal adjustment including trading assignments to eliminate the need to do jobs that caused fear or discomfort, drawing on the construction expertise of more experienced collaboration members to fix volunteer errors, and engaging a bilingual collaboration member to translate for the site leader and the Spanish-speaking collaborator.

Further, there were some collaborations identified as being highly heterogeneous and as having experienced high levels of external challenges that also engaged in multiple instances of internal adjustment. As an example, the Rainforest collaboration was a highly heterogeneous group (including a large number of Costa Ricans and individuals from the United States; collaborators ranging in age from late teens or 20s to late 70s; individuals representing a wide variety of functional backgrounds; individuals with a wide range of experience with humanitarian home building projects; and a mix of men and women) that experienced a high level of external challenges. This group also engaged in internal adjustments that were likely facilitated by the diversity that characterized their internal composition. For example, tasks such as painting that required precision and involved 
collaborators without shared history or the ability to speak the same language proved to be a challenge. One participant related the following:

"The rest of us in our 50s-70s were plodding along but taking great care in not slopping the paint on and getting it on the floor. In contrast, [three young girls from San Jose, probably just out of high school] proceeded with enthusiastic rapidity-and did get the remaining wall completed in no time. We were out of a job, except to clean up their spills...We were very relieved that all the wood and window frames had been expertly taped by an experienced [participant] before they blew in!”

This experienced participant who did the taping had previously owned an auto body shop and had professional experience in taping and painting. This woman's experience allowed the collaboration to adjust to the external challenge created by the precise nature of the work that was compounded by lack of shared history and language barriers. In this case, it was functional heterogeneity that allowed this collaboration to adjust to challenges that may have been caused in part by cultural differences and language barriers.

It is also interesting to note that the highly heterogeneous Rainforest collaboration that experienced a number of external challenges tried to deal with many of these challenges via internal adjustment (rather than external adjustment). For example, they adjusted to a culture clash by doing some task rescheduling and having conversations to try to resolve the issue. They also adjusted to rainy conditions by adapting their schedule and making some changes to their tasks. As this collaboration's experience illustrates, certain types of external challenges may require an internal focus (e.g., attempting to resolve internal conflicts that result from cultural differences).

But some types of external challenges experienced by the collaborations we examined appeared to require both internal and external adjustment. For example, on the highly heterogeneous Rainforest collaboration mentioned above, there were a variety of leaders responsible for different aspects of the project. The Costa Rican construction lead (an external contractor) was in charge of the professional construction crew and all technical construction plans and processes. The North American brigade leaders who had organized all of the volunteers that had come from the United States and had invited guests from San Jose, were in charge of making work assignments and taking care of the logistical needs of the participants. The Costa Rican volunteer coordinator for 
the project was in charge of coordinating with the brigade leaders as well as neighbors and Rainforest locals to participate in the construction effort, as well as managing the schedule and experience of the North American volunteers. External challenges that might result from such a collaboration structure include cultural challenges, language barriers, and challenges related to coordinating processes and responsibilities among internal and external leaders. Some challenges of this nature would likely result from the fluid, temporary nature of the project and may be generalizable to collaborations in a variety of other contexts. Adjustment in such cases may very well require both internal and external adjustment. In particular, examples of external adjustments to external challenges that might be required in this context might include negotiating with regulatory agencies to obtain permits, engaging or releasing external contractors to adapt to scheduling challenges, and resolving conflicts with neighbors that may occur during the construction process.

The question then becomes, why might a culturally heterogeneous collaboration be better at adjusting? Here, we draw upon and extend the research of Joshi and Roh (2009), who argued that the short duration of project teams provides incentive for members to focus less on conflict-provoking aspects of heterogeneity and focus instead on how to leverage heterogeneity for the benefit of the group. Hence, they are able to take even greater advantage of the diverse knowledge, skills and perspectives that exist in the team. Along these lines, we suggest that the presence of a high level of challenges may provide an impetus for collaborations to harness their heterogeneity toward making critical adjustments, and provide an incentive to focus less on conflict-generating heterogeneity and more on differences that can be leveraged for overcoming challenges. As a result they may be even better able to adjust than less heterogeneous collaborations. The potential for process losses still exist, but the salient and substantial challenges “trump” the internal strife, either keeping it dormant, or possibly eradicating it, as the collaboration rallies its diverse knowledge, skills, and networks to address the challenges. As we depict in Figure 1, we would argue that because they do not have the resources that an organization context often provides, collaborations need to be all the more inventive in addressing the challenges they face, which likely amplifies the processes mentioned above, such that the culturally heterogeneous collaboration is even better able to put aside conflict-provoking aspects of heterogeneity, and therefore make better use of its diversity. 


\section{What Is the Relationship Between Collaboration Adjustment and Performance?}

In addition to refining our understanding of the types of challenges and adjustments collaborations in our sample experienced, we were also interested in knowing whether there is a relationship between collaboration adjustment and performance. Interestingly, our observations suggest the possibility that collaborations may overadjust when adjustment takes place in the absence of a pressing need. That is, in response to a mild or less significant challenge, collaborations may be overly responsive, and this may negatively impact collaboration effectiveness. Gibson and Dibble (2012) refer to this phenomenon in their study of film making teams as "selling out", and found that in collaborations that were temporary and fluid, and where environmental volatility was high, the extent to which collaborations externally adjusted reached a point of diminishing returns. That is, a certain amount of interaction with external constituents was critical, but an excessive amount of external adjustment was harmful to the collaborations’ effectiveness, because it was so destabilizing that collaborators lost focus. In the extreme, the original vision and goals for the collaboration were sometimes compromised, and film viewers (e.g., the external customer in the film making context) detected this, rating the films as less effective. Yet Gibson and Dibble (2012) focused only on external adjustment, did not examine the role of the extent to which challenges were faced, nor the role of cultural heterogeneity, and so we extend their research. In the next section, we address the question, if appropriate levels of adjustment (i.e., adjusting only to the extent to which adjustment is required) is critical to a collaboration, and too much adjustment is detrimental, what determines the requisite level of adjustment for a collaboration and what is the mechanism by which adjustment may benefit performance? We summarize our findings in this regard in Table 4.

Insert Table 4 Here

Internal Adjustment and Performance. Our observations suggest that the relationship between internal adjustment and collaboration performance will depend on the extent to which internal challenges are experienced. That is, when there are few internal challenges, extensive modification of the ways in which 
collaborators work together appear to result in cognitive and emotional overload for participants, in that they experience disorientation, confusion and a reduction in critical resources. Hence, unnecessary or excessive change has a variety of deleterious effects including misdirection of critical resources in addition to creating needless anxiety and frustration among those required to enact the change. Our observations indicate that optimal performance occurs when the extent of adjustment is appropriate for the intensity of the challenge experienced.

Among those collaborations that experienced low levels of internal challenges, we found some evidence of a negative impact of internal adjustments on performance. Conversely, the collaboration with the highest overall performance experienced few internal challenges and engaged in very little internal adjustment. As an example of the negative impact of significant internal adjustment in the absence of challenges, consider the example of the Latin Outskirts collaboration, where extensive adjustments were requested of the home building association by the home owners. Silvia, the owner of one of the homes described her requests for adjustments:

We would tell them “Don't use that. Don't do that.” They would say “Okay...” They don't want walls. They don't want windows. They don't want that. Those were the changes. Nothing too complicated. We just needed to watch the workers and tell them "No, not this."

The extensive changes included installing special doors, windows, and other features that were not part of the standard footprint for the homes being built. These adjustments were not in response to a major internal challenge; they appeared to be adjustments made to suit the whims of the recipients. The result of these changes was poor overall performance as captured by our observation of the completed home, and the satisfaction of the home owners. For example, when asked about how satisfied they were with the quality of the house and the time it took to build the home (on a scale of 1 to 5 , with 5 being very satisfied) the home owner provided the following assessment:

I can't really give it a 5 because there are things that are still not right. 3. [And regarding the time it took to build the home], also 3 because they gave us a date and didn't meet it.

Hence, it appears internal adjustments should be undertaken with caution, as the detriments of over-adjustment may be substantial. 
There is some corroborating support for this relationship in the existing literature. While no research that we are aware of has examined collaboration internal adjustment as we have defined it here, recent literature has focused on specific forms of internal adjustment and its implications for performance, suggesting that the relationship between internal adjustment and performance may not be a simple, positive, linear relationship. For example, Gurtner et al. (2007) conducted an experiment to test whether groups performed better when they were directed to engage in individual or group reflexivity (reflection about group objectives, strategies, and processes, and subsequent adaptation) or in a control context. Group reflexivity here is similar to internal adjustment in the sense that it involves adapting the ways groups work together (i.e., adapting group objectives, strategies or processes) in response to the challenge of dealing with information asymmetry; however, reflexivity implies more overt reflection and strategizing about potential adjustments to challenges, while internal adjustment implies a more spontaneous, unplanned approach. Contrary to their expectations, Gurtner et al. (2007) found that performance for groups that engaged in group reflexivity was not significantly different from those that engaged in individual reflexivity and that patterns indicated better (rather than worse) performance among those that engaged in individual reflexivity than those engaging in group reflexivity. As in our own data, this study indicates that outcomes of collective adjustment are complex and potentially moderated by other factors. While our focus here is on the moderating effect of challenges experienced by the collaboration, other potential moderators may also exist, such as the stage in the collaboration life cycle at which the adjustment takes place and the extent to which the challenge is perceived as significant across the collaboration membership. Future research should examine these issues as well as the ways in which the nature of the challenge and the nature of the adjustments figure into the adjustment-performance relationship.

External Adjustment and Performance. Our study provides some evidence of a positive relationship between external adjustment and performance when a collaboration experienced high levels of external challenges. For example, the Latin City 1 collaboration, which was coded as better than average performance, experienced several external challenges such as having their water turned off at their hotel and experiencing language translation and measurement translation challenges. To cope, this collaboration changed the way they interacted with their external stakeholders (e.g., they changed the way they worked with contractors by using translators, 
and their hotel owner negotiated with another local hotel for them to use their facilities until the water was restored) in order to externally adjust.

While we're not aware of any empirical studies that have examined the relationship between external adjustment (as defined here) and performance in the context of collaborations, the literature has identified a variety of ways in which collaboration-like entities respond to changes in their external environment and the outcomes associated with these adjustments. For example, Ancona et al. (2002) conducted an empirical study that provided evidence that adaptive teams (e.g., “x-teams”) with an external orientation are useful in overcoming the challenges associated with dynamic work conditions, technology and customer demands, and suggested that the use of these teams may be related to higher performance, especially when organizational structures are flat with multiple alliances; when teams are dependent on complex, dispersed, and rapidly changing information; and when organizational tasks are intertwined with external tasks. However, they did not provide in-depth empirical results regarding the relationship between adjustment vís a vís external stakeholders and performance, nor did they examine multicultural collaborations, hence our findings extend their important work and address that critical gap in the existing literature.

Research on concepts similar to collaboration external adjustment, albeit at the firm level of analysis, has produced equivocal results with regard to the relationship between adjustment and performance. That is, while some research has suggested that adjustment leads to better performance, other research has suggested that the relationship may not be positive and linear and may be moderated by context. For example, Lumpkin and Dess (2001) conducted a study at the firm level of analysis where they drew upon a sample of executives from 94 firms to examine the ways in which firms adapt to the challenges of environmental opportunities and threats. Their findings suggested that firm adaptations in the form of proactiveness (an opportunity-seeking strategy that seeks to anticipate future demand) is more likely to result in high performance when firms operate in dynamic environments and growth industries than when environmental dynamism is low, and that adaptations in the form of competitive-aggressiveness (defined as the effort by a firm to outperform rivals by assuming a combative posture) are more likely to be associated with high performance for firms operating in hostile environments than in contexts where environmental hostility is low. They concluded that not all dimensions of adaptations to 
environmental conditions will be positively related to performance under all conditions. Here we shed further light on the complex relationship between external adjustment and performance at the collaboration level of analysis, noting that in our data, it was important that collaborations matched the extent to which they adjusted with the degree to which they experienced challenges. Otherwise, performance may suffer. While these ideas are important at the organizational level of analysis, they are perhaps even more critical at the collaboration level, given that financial and human resources may be even more finite, and that collaborations may be operating without the benefit of support from an overarching organization.

Cultural Challenges, Adjustment and Performance. Our analysis revealed that in all collaborations for which we documented a language and/or cultural challenge, the performance for these collaborations never exceeded a "moderate" rating. That is, these collaborations were unfortunately among our lowest performing. In fact, in the very lowest performing collaboration (the Latin Outskirts collaboration described above), we observed a couple of important cultural and language challenges. For example, as mentioned earlier, one challenge involved the expectation by the American participants that the recipient family would help them with their work on the home (the female recipient came to watch but never participated in the work), without uncovering the cultural bias against women working in construction in Costa Rica. Additionally, this collaboration experienced a critical language barrier between the construction contractor (i.e., the individual with the construction expertise) and the volunteers.

Hence, it is possible that the most common adjustment strategies used by collaborations are not sufficient to address the types of cultural and language-related challenges frequently experienced by multicultural collaborations. However, given the increasingly important nature of multicultural teams and collaborations, the appropriate level and type of response to this variety of challenges is a critical topic for future research, as we discuss below.

\section{DISCUSSION}

Traditionally organizational scholars have conceptualized teams as groups of organizationally co-located individuals who are assigned to an effort on which they collaborate for a defined period of time. But what 
happens when globalization and contextual requirements necessitate collaboration in entities whose composition is multicultural and changes frequently, whose participants may not be embedded within a single overarching organization, and who may not have a formal leader? Can these collaborations become equally or perhaps even more effective than their conventional counterparts at responding to the challenges that come their way? Some provocative answers to these questions can be found in the observation of humanitarian home building collaborations.

Specifically, we found that multicultural collaborations adjust to internal and external challenges using both internal and external adjustment techniques, and that collaborations utilize a range of strategies for adjusting. We also found some evidence that when collaborations experience internal challenges related to the way they work together, cultural heterogeneity may contribute to the ability to make important adjustments. Additionally, our study provides some evidence that the detriments of internal over-adjustment (significant internal adjustments in the absence of a significant challenge) may be substantial. Finally, we found some evidence that in the presence of external challenges, external adjustments may be related to performance.

\section{Theoretical Contributions}

This research extends prior research in new and interesting ways, including examining the variety of ways multicultural collaborations respond to challenges and the implications of collaborations as hybrid forms of organizing.

Collaboration Responses to Change. As noted above, our research extends Ancona and Caldwell's (1992) examinations of the impact of the type and amount of teams' engagement with external entities on performance. First, we extend their research into new contexts characterized by more complex environments. Most of their research pertains to teams situated within an overarching organization, yet here, many of the collaboration participants under consideration had no common organizational affiliation. Second, while Ancona and Caldwell's (1992) work enabled a classification of strategies that teams adopted and the frequency of external contact, our research builds theory regarding the nature of the adjustments collaborations made to challenges they experienced in both their internal and external environments. 
To our knowledge, no research has conducted a simultaneous empirical examination of internal and external adjustment as we have defined these concepts here. While past research has captured critical elements of each, none that we are aware of has captured a range of the elements of internal and external adjustment necessary to fully understand how each impacts performance in fluid, temporary, multicultural collaborations that are interpenetrated by their external environments. Further, prior research on concepts related to adjustment at other levels of analysis cannot be generalized to address these issues in the context of a collaboration. While some of this research conducted at other levels of analysis will be helpful in understanding collaboration adjustment (e.g., conflict resolution in teams) other research focused on change and learning in more stable, conventional organizational forms will need to be adapted to apply to collaborative forms of organizing where there is no prior history to draw upon, where there is no expectation of continuing work together (and hence reduced incentive to forge cohesive units), where there is no overarching organizational or functional loyalty, and where the collaboration may have so little information about their environment or the projected outcomes of their labor that they may not be able to proactively develop contingencies to avoid potential problems.

Adjustment strategies. We found that among our sample of humanitarian home building collaborations the most frequent adjustment/challenge combination was internal adjustment to external challenges (52\%), with the second most frequent combination being internal adjustment to internal challenges (32\%). In addition, our observations indicated that type of adjustment is situated along a continuum ranging from less complex to more intricate forms of adjustment with respect to the changes required to the structure of the collaboration and the involvement of few versus many individuals. For example, a simple adjustment might be including more frequent rest breaks in the day’s work schedule as a result of hot sun and hard labor. A more complex type of adjustment was exemplified by a group of collaborations that re-organized in order to facilitate volunteer involvement. The effect of adjustment strategies on performance appears to depend at least to some extent on the degree to which there is a just cause for the adjustment, but also likely depends on the extent to which members perceive them as salient. Due to the fluid nature of participation in collaborations and the fact that collaborations are more permeable with their external environments, external 
challenges are likely to be more intense than in those described in the literature on conventional, organizationally embedded teams. As mentioned earlier, in teams that exist within an organization, the firm often buffers them from the external environment, or at least attempts to reduce the uncertainty about the environment through their history of external relationships with suppliers, customers, other organizations, agencies, or governing bodies. But because collaborations are composed of individuals affiliated with a variety of external constituents with conflicting needs or interests, and given the lack of organization structures, resources, and scripts for dealing with external challenges, such challenges may be more difficult to resolve, yet even more important to address. Multicultural collaborations may be a form of organizing particularly well suited to respond to external challenges and adjust.

Further, although challenges that were cultural in nature were among the most difficult to resolve, we found that shifts in leadership may be an effective means of doing so. This extends prior research which has examined how shifting leadership can be beneficial in teams (e.g., Klein et al. 2006), by examining the role of such shifts in multicultural collaborations. Again, the lack of organizational embeddedness adds a unique element to the practice of shifting leadership, because there may be no formal mechanisms for designating leaders and rotation of leadership, and/or such roles may be implicit. Multiculturalism complicates shifts in leadership because some cultures (e.g., those high in power distance, see Gibson \& McDaniel (201므) for a review) rely on and expect a clearly defined authority structure, and hence may be less responsive to such a strategy. However, even in such a context (i.e., Costa Rica), the collaborations in our sample were able to implement shifting leadership to address challenges related to culture and language. Future research should examine whether there are other types of adjustment strategies best suited to the successful resolution of cultural challenges. Additionally, future research should seek to identify whether there are certain types of challenges that cannot be resolved by common adjustment strategies. We wonder whether shifting leadership exists primarily in collaborations and other alternative forms of organizing, or whether it is widespread yet masked by formal roles within traditional organizations. Additionally, future research might examine how these shifts in leadership take place and whether this is a type of adjustment that may be deliberately orchestrated or whether emergent leadership is most successful when it occurs spontaneously. 
Collaborations as Hybrid Forms of Organizing. The teams literature has traditionally focused on constructs internal to the team such as member turnover, team commitment, team reflexivity, and team heterogeneity (e.g., Arrow \& McGrath, 1993; Pearce \& Herbik, 2004; Schippers, Den Hartog, Koopman, \& Wienk, 2003; Joshi \& Roh, 2009, etc.), while the organizations literature has focused on those which are external (e.g., firm adjustment to challenges regarding governance misalignment through renegotiating contracts vís a vís their alliance partners, Arino et al., 2008). In some respects, collaborations are a hybrid between teams and organizations - they enjoy more independence, have more fluid membership, and fuzzier boundaries than conventional teams, but are generally temporary and are not as well endowed with resources as are formal organizations. Perhaps corresponding with this, it is interesting to note that $52 \%$ of the observations of adjustments to challenges were internal adjustments to external challenges, yet as we noted earlier, there are likely circumstances, particularly in collaborations when external adjustments are critical. We anticipate there are many other unique features of collaborations which will result in the need for such forms to adjust in novel ways, providing a rich arena for future research on collective work efforts.

For example, we identify membership issues as an important means of differentiating collaborations from other alternative forms of organizing. That is, collaborations are characterized by fluid membership, as members frequently begin and complete their work on a collaboration at different times. This results in blurred boundaries, as it is often challenging to determine who is "internal" and who is "external" to a collaboration. As a result of the blurred boundaries, it is likely that concepts we have taken for granted in the organizational behavior literature, such as commitment, turnover, and participation have different norms and rules in collaborations.

Finally, the collaborations in our sample varied in the degree to which they adjusted and how. This may have been due to the extent to which they resemble formal conventional teams, and future research might investigate defining properties of collaborations and how they affect adjustment. However, the variance is 
also likely due to different adjustment-related skill sets on the collaborations. This highlights the possibility that training for adjustment in multicultural collaborations would be a useful avenue to pursue.

\section{Implications for Practice}

Given the proliferation of work that occurs in collaborations, it is important to begin a collaborative venture with a sense of the types of challenges that may ensue as well as options for adjustment. For example, project managers preparing to begin a collaborative work effort may find it useful to review the typology captured in Table 2, considering the types of internal and external challenges that they may face, along with the resources and constraints they have available to respond to these challenges. While it is impossible to foresee all challenges that a collaboration will face in advance, some challenges related to the nature of the work, language barriers, and technological complexities can be alleviated by proper attention to team composition (i.e., ensuring that a requisite diversity of skills are available or within reach).

Another important practical implication of this research is related to the way in which cultural challenges are managed. For example, we found that cultural challenges were among the most difficult types of challenges that collaborators experienced and in some cases these were never really addressed. We recommend that managers of multicultural collaborations pay particular attention to challenges that have their roots in cultural misunderstandings. While it is impossible to eliminate cultural differences among multicultural collaborators, it is possible to create forums for better understanding norms, expectations, biases, and taboos that participants from various cultures bring with them. An increased awareness of and appreciation for cultural differences would likely allow collaboration members to adjust to cultural challenges by selecting a more effortful and effective means of adjustment than the default method of "retreating".

One particular method of adjusting to cultural challenges is shifting leadership roles. Our research provides evidence that shifts in leadership may be a beneficial means of adjusting to cultural and language challenges. While these types of shifts may occur in unstructured ways, deliberately assigning leadership roles to individuals who have critical cultural knowledge and language skills may be a key to making adjustments to cultural challenges in multicultural collaborations.

\section{Limitations and Future Research}


The careful design of the field study is a major strength of this research. However, it is possible that in developing the key constructs, we may have created something of a "false distinction" between challenges, adjustments, and performance in the sense that often times there are a series of events that take place for a collaboration in which the same event can be classified as a challenge, an adjustment, or an outcome. For example, a participant error might contribute to failing an inspection, which might in turn contribute to the challenge of not being able to keep working on a particular aspect of construction, which might result in a lack of work. Any one of these events might be considered a challenge, an adjustment (e.g., reducing the amount of work performed on a site), or an outcome. Our strategy was to select elements of the cycle on which to focus for "challenges” based on what was most salient for participants (e.g., lack of work), hence our findings are grounded in the actual experience of those who worked on the collaborations. However, we note that these distinctions are a ripe area for future research, in which experience sampling techniques (e.g., hourly responses to a set of queries) might be an appropriate method to investigate these distinctions. In pursuing this line of research, it will be important to sample an even greater number of completed collaborations than we included, or to observe them from start to finish, so as to understand whether experiences of challenges, adjustment and outcomes change over the life of the collaboration.

Developmental processes in collaborations is also unchartered territory. The collaborations that we observed developed in a variety of ways. For example, some collaborations were comprised of individuals who knew each other prior to beginning their day's work and other collaborations were comprised primarily of strangers. Although our data do not allow us to draw conclusions regarding the relationship between collaboration development and subsequent adjustment and performance, we suspect that some shared knowledge regarding the diverse skills and experience of participants (such as conducting a "skills inventory” at the outset in collaborations) would allow a team to be even more successful in harnessing their diversity to adjust. We encourage future research along these lines.

Another potential limitation of this research is that in this particular context, it appears that there may have been less opportunity for many collaboration participants to interact with external stakeholders, such that adjusting vís a vís external collaborators may have not been viewed as a feasible option. Rather, some 
collaborators reported that interaction with external stakeholders was mostly accomplished by site leaders. Future research should examine contexts with fewer constraints on interaction with external stakeholders, such as open source software development, to determine if our findings regarding external adjustment hold when there is greater opportunity for interface.

In addition, we considered primarily national culture, based on national background, because this was salient for our participants. However, a finer grained distinction could focus on specific cultural orientations or attributes. For example, future research should examine the impact of universalism and particularism on collaboration adjustment. Universalism is defined as an "understanding, appreciation, tolerance and protection for the welfare of all people and for nature" (Schwartz, 1996: 3), while particularism "refers to actions based on an exclusive attachment to one’s own group, nation, family, or circle of friends” (Pearce, 2001). Such research might examine whether collaboration participants who are more universalistic may be more likely to use multiple types of internal and external adjustment techniques in response to challenges in their internal and external environments, while collaboration members who are more particularistic may be more likely to use one main type of adjustment technique in response to challenges in their internal and external environments. Again, perhaps one of these routes is more optimal than the other.

Additionally, future research should examine the ideas presented here in a for-profit context. Parallel studies of for-profit and not-for-profit collaborative endeavors might be conducted in the context of construction projects (e.g., commercial building collaborations examined alongside collaborations similar to those included in the current study); for-profit and not-for-profit software and video game development (e.g., an examination of collaborations developing video games for social or educational purposes in the non-profit sector examined alongside collaborations engaged in the development of commercial products); or humanitarian and for-profit health care (e.g., an examination of humanitarian surgical teams alongside similar teams in for-profit hospital systems). Such research—particularly a combination of studies across multiple industries — would broaden our understanding of the antecedents to internal and external adjustment, as well as the impact of internal and external adjustment on collaboration effectiveness. We expect that many 
of our findings will be generalizable across industries and across for-profit and non-profit contexts; however, this is an empirical issue yet to be addressed.

\section{Conclusion}

In conclusion, this research makes several important contributions to theory and to practice. First, we contribute to the establishment of a definition for collaborations, comparing and contrasting collaborations to other similar constructs in the literature and arguing that this is an important and distinct organizational form. Further, this research addressed important questions with respect to the most common challenges that face multicultural collaborations and how these collaborations adjust. Analysis of our data indicates that while collaborations in this sample faced more external challenges, their responses were overwhelmingly "internal” in nature, yet some of the important adjustments they implemented were external. Additionally, our analysis suggests that collaboration heterogeneity may facilitate adjustment, and that over adjustment may be

detrimental, implying a need to identify optimal levels of adjustment. Finding the right strategies for adjustment contributes to collaborating for the common good. 


\section{REFERENCES}

Ancona, D., Bresman, H., \& Kaeufer, K. 2002. The comparative advantage of X-teams. MIT Sloan Management Review, Spring 2002: 33-39.

Ancona, D. \& Bresman, H. 2007. X-Teams: How to Build Teams that Lead, Innovate, and Succeed. Boston, MA: Harvard Business School Publishing.

Ancona, D. G. \& Caldwell, D. F. 1992. Bridging the boundary: External activity and performance in organizational teams. Administrative Science Quarterly, 37: 634-665.

Ariño, A., Ragozzino, R., \& Reuer, J. J. 2008. Alliance dynamics for entrepreneurial firms. Journal of Management Studies, 45: 147-168.

Arrow, H. \& McGrath, J. E. 1993. Membership matters. Small Group Research, 24(3): 334-361.

Avolio, B. J., Jung, D. I., \& Sivasubramaniam, N. 1996. Building highly developed teams: Focusing on shared leadership processes, efficacy, trust, and performance. In M. M. Beyerlein \& D. A. Johnson (Eds.), Working Papers in Theory of Action: 111-161, Glencoe, IL: Free Press.

Baker, T. \& Nelson, R. E. 2005. Creating something from nothing: Resource construction through entrepreneurial bricolage. Administrative Science Quarterly, 50: 329-366.

Bechky, B. A. 2006. Gaffers, gofers, and grips: Role-based coordination in temporary organizations. Organization Science, 17(1): 3-21.

Carson, J. B., Tesluk, P. E., \& Marrone, J. A. 2007. Shared leadership in teams: An investigation of antecedent conditions and performance. Academy of Management Journal, 50(5): 1217-1234.

Corley, K. G., and D. A. Gioia. 2004 Identity ambiguity and change in the wake of a corporate spin-off. Administrative Science Quarterly, 49: 173-208.

Coultas, C., Grossman, R., Feitosa, J., Salas, E. \& Carter, N. 2012. Training for Cultural Competence: A Meta-Analysis. Paper to be presented at the Society of Organizational Behavior National Conference, San Diego, CA.

Eisenhardt, K.M. 1989. Building Theory from Case Study Research. Academy of Management Review, 4(4): 532-550.

Eisenhardt, K.M. 1991. Better stories and better constructs: The case of rigor and comparative logic. Academy of Management Review, 16: 620-627.

Ely, R. J. \& Thomas, D. A. 2001. Cultural diversity at work: The effects of diversity perspectives on work group processes and outcomes. Administrative Science Quarterly, 46: 229-273.

Ensley, M. D., Hmieleski, K. M., \& Pearce, C. L. 2006. The importance of vertical and shared leadership within new venture top management teams: Implications for the performance of startups. Leadership Quarterly, 17: 217-231. 
Fiedler, F. E. 1964. A contingency model of leadership effectiveness. In L. Berkowitz (Ed.), Advances in Experimental Social Psychology. New York: Academic Press.

Gephart, R. P.2004. Qualitative research and the Academy of Management Journal. Academy of Management Journal, 40: 454-462.

Gioia, D. A., and K. Chittipeddi, K. 1991 Sensemaking and sensegiving in strategic change initiation. Strategic Management Journal, 12: 433-448.

Gibson, C. B. \& Dibble, R. 2008. Culture inside and out: Developing a collaboration's capacity to externally adjust. In S. Ang \& L. Van Dyne (Eds.), Handbook on Cultural Intelligence. New York: M. E. Sharpe.

Gibson, C. B. \& Zellmer-Bruhn, M. 2001. Metaphors and meaning: An intercultural analysis of the concept of teamwork. Administrative Science Quarterly, 46(2): 274-303.

Gibson, C. B. \& Vermeulen, F. 2003. A healthy divide: Subgroups as a stimulus for team learning behavior. Administrative Science Quarterly, 48: 202-239.

Gibson, C.B. \& McDaniel, D.M. 20101. Moving Beyond Conventional Wisdom: Advancements in Crosscultural Theories of Leadership, Conflict, and Teams, Perspectives on Psychological Science, 5(4) 450-462.

Gundry, L., \& Rousseau, D. 1994. Critical incidents in communicating culture to newcomers: the meaning is the message. Human Relations, 47: 1063-1087

Gurtner, A., Tschan, F., Semmer, N. K., \& Nagele, C. 2007. Getting groups to develop good strategies: Effects of reflexivity interventions on team process, team performance, and shared mental models.

Organizational Behavior and Human Decision Processes, 102: 127-142.

Hoffman, L. R., \& Maier, N. R. F. 1961. Quality and acceptance of problem solutions by members of homogeneous and heterogeneous groups. The Journal of Abnormal and Social Psychology, 62(2): 401-407.

Holsti, O. R. 1969. Content Analysis for the Social Sciences and Humanities. Reading, MA: AddisonWesley.

Jackson, S. E., Brett, J. F., Sessa, V. I., Cooper, D. M., Julin, J. A., Peyronnin, K. 1991. Some differences make a difference: Individual dissimilarity and group heterogeneity as correlates of recruitment, promotions, and turnover. Journal of Applied Psychology, 76(5): 675-689.

Joshi, A. \& Roh, H. 2009. The role of context in work team diversity research: A meta-analytic review. Academy of Management Journal. 
Katz, A. \& Te'eni, D. 2007. The contingent impact of contextualization on computer-mediated collaboration. Organization Science, 18(2): 261-279.

Klein, K. J., Ziegert, J. C., Knight, A. P., \& Xiao, Y. 2006. Dynamic delegation : Shared, hierachical, and deindividualized leadership in extreme action teams. Administrative Science Quarterly, 51 : 590-621.

Lumpkin, G. T. \& Dess, G. G. 2001. Linking two dimensions of entrepreneurial orientation to firm performance: The moderating role of environment and industry life cycle. Journal of Business Venturing, 16: 429-451.

Mayring P. 2000. Qualitative Content Analysis. Forum: Qualitative Social Research, 1(2).

Moorman, C. \& Miner, A. S. 1998. The convergence of planning and execution: Improvisation in new product development. Journal of Marketing, 62: 1-20.

Pearce, J.L. 2001. Organization and management in the embrace of government. New Jersey: Lawrence Erlbaum Associates.

Pearce, C. L. \& Herbik, P. A. 2004. Citizenship behavior at the team level of analysis: The effects of team leadership, team commitment, perceived team support, and team size. The Journal of Social Psychology, 144(3): 293-310.

Salas, E. \& Gelfand, M. 2011. Call for Papers: Collaboration and Negotiation in Multi-Cultural Environments. Journal of Organizational Behavior.

Samra, Y. M., Lynn, G. S., \& Reilly, R. R. 2008. Effect of improvisation on product cycle time and product success: A study of new product development (NPD) teams in the United States. International Journal of Management, 25(1): 175-185.

Schippers, M. C., Den Hartog, D. N., Koopman, P. L., \& Wienk, J. A. 2003. Diversity and team outcomes: The moderating effects of outcome interdependence and group longevity and the mediating effect of reflexivity. Journal of Organizational Behavior, 24: 779-802.

Schwartz, S. 1996. Value priorities and behavior: Applying a theory of integrated value systems. In C. Seligman, J. M. Olson, and M. P. Zanna (Eds.). The Psychology of Values: The Ontario Symposium Volume 8: 1-24. Mahwah, NJ: Lawrence Earlbaum Associates, Inc.

Strauss, A. 1987. Qualitative Analysis for Social Scientists. New York: Cambridge University Press.

Vallaster, C. (2005). Cultural Diversity and Its Impact on Social Interactive Processes: Implications from an Empirical Study, International Journal of Cross-cultural Management, 5(2): 139-163.

Wagner, W. G., Pfeffer, J., \& O’Reilly, C. A., 1984. Organizational demography and turnover in topmanagement group. Administrative Science Quarterly, 29(1): 74-92. 
Watson, W. E., Kumar, K., \& Michelson, L. K. 1993. Cultural diversity’s impact on interaction processes and performance : Comparing homogeneous and diverse task groups. Academy of Management Journal, 35 : 590-602.

Weber, R. P. 1985. Basic Content Analysis. Beverly Hills, CA: Sage.

Yin, R. 1994. Case Study Research: Design and Methods. $2^{\text {nd }}$ ed., Thousand Oaks, CA: Sage.

Zimmermann, A. \& Sparrow, P. 2007. Mutual adjustment processes in international teams: Lessons for the study of expatriation. Int. Studies of Mgt. \& Org., 37(3): 65-88. 
TABLE 1

Description of Collaborations Included in the Sample

\begin{tabular}{|c|c|c|c|c|c|}
\hline $\begin{array}{l}\text { Collaboration } \\
\text { Number }\end{array}$ & Collaboration & Country & $\begin{array}{c}\text { Approx. } \\
\text { Number of } \\
\text { Participants }\end{array}$ & $\begin{array}{c}\text { Approx. } \\
\text { Hours }\end{array}$ & $\begin{array}{c}\text { Stages } \\
\text { Observed }\end{array}$ \\
\hline 1 & $\begin{array}{l}\text { Suburbia } \\
\text { (Visit \#1) }\end{array}$ & USA & 7 & 6 & Middle \\
\hline 2 & $\begin{array}{l}\text { Suburbia } \\
\text { (Visit \#2) }\end{array}$ & USA & 9 & 3 & Middle \\
\hline 3 & $\begin{array}{l}\text { Suburbia } \\
\text { (Visit \# 3) }\end{array}$ & USA & 40 & 4 & Middle \\
\hline 4 & City (Visit \#1) & USA & 20 & 6 & Beginning \\
\hline 5 & $\begin{array}{c}\text { Latin } \\
\text { Outskirts }\end{array}$ & $\begin{array}{l}\text { Costa } \\
\text { Rica }\end{array}$ & 13 & 10 & Beginning \\
\hline 6 & City (Visit \#2) & USA & 13 & 5 & Middle \\
\hline 7 & City (Visit \#3) & USA & 18 & 4 & Middle \\
\hline 8 & $\begin{array}{l}\text { Inner City } \\
\text { (Visit \#1) }\end{array}$ & USA & 20 & 3 & Middle \\
\hline 9 & $\begin{array}{l}\text { Inner City } \\
\text { (Visit \#2) }\end{array}$ & USA & 15 & 6 & Middle \\
\hline 10 & $\begin{array}{l}\text { Inner City } \\
\text { (Visit \#3) }\end{array}$ & USA & 7 & 5 & Middle \\
\hline 11 & $\begin{array}{l}\text { Latin City } \\
\text { (Visit \#1) }\end{array}$ & $\begin{array}{l}\text { Costa } \\
\text { Rica }\end{array}$ & 30 & 16 & Beginning \\
\hline 12 & Rainforest & $\begin{array}{l}\text { Costa } \\
\text { Rica }\end{array}$ & 50 & 12 & $\begin{array}{l}\text { Beginning, } \\
\text { Middle, \& } \\
\text { End }\end{array}$ \\
\hline 13 & $\begin{array}{l}\text { Coastal } \\
\text { (Visit \#1) }\end{array}$ & USA & 9 & 7 & Middle \\
\hline 14 & $\begin{array}{c}\text { Coastal } \\
\text { (Visit \#2) }\end{array}$ & USA & 30 & 7 & Middle \\
\hline 15 & $\begin{array}{l}\text { Suburbia } \\
\text { (Visit \#4) }\end{array}$ & USA & 20 & 5 & End \\
\hline 16 & $\begin{array}{l}\text { Latin City } \\
\text { (Visit \#2) }\end{array}$ & $\begin{array}{l}\text { Costa } \\
\text { Rica }\end{array}$ & 25 & 15 & $\begin{array}{l}\text { Beginning } \\
\text { \& Middle }\end{array}$ \\
\hline
\end{tabular}


TABLE 2

Internal and External Challenges Experienced by Collaborations and Internal and External Adjustments

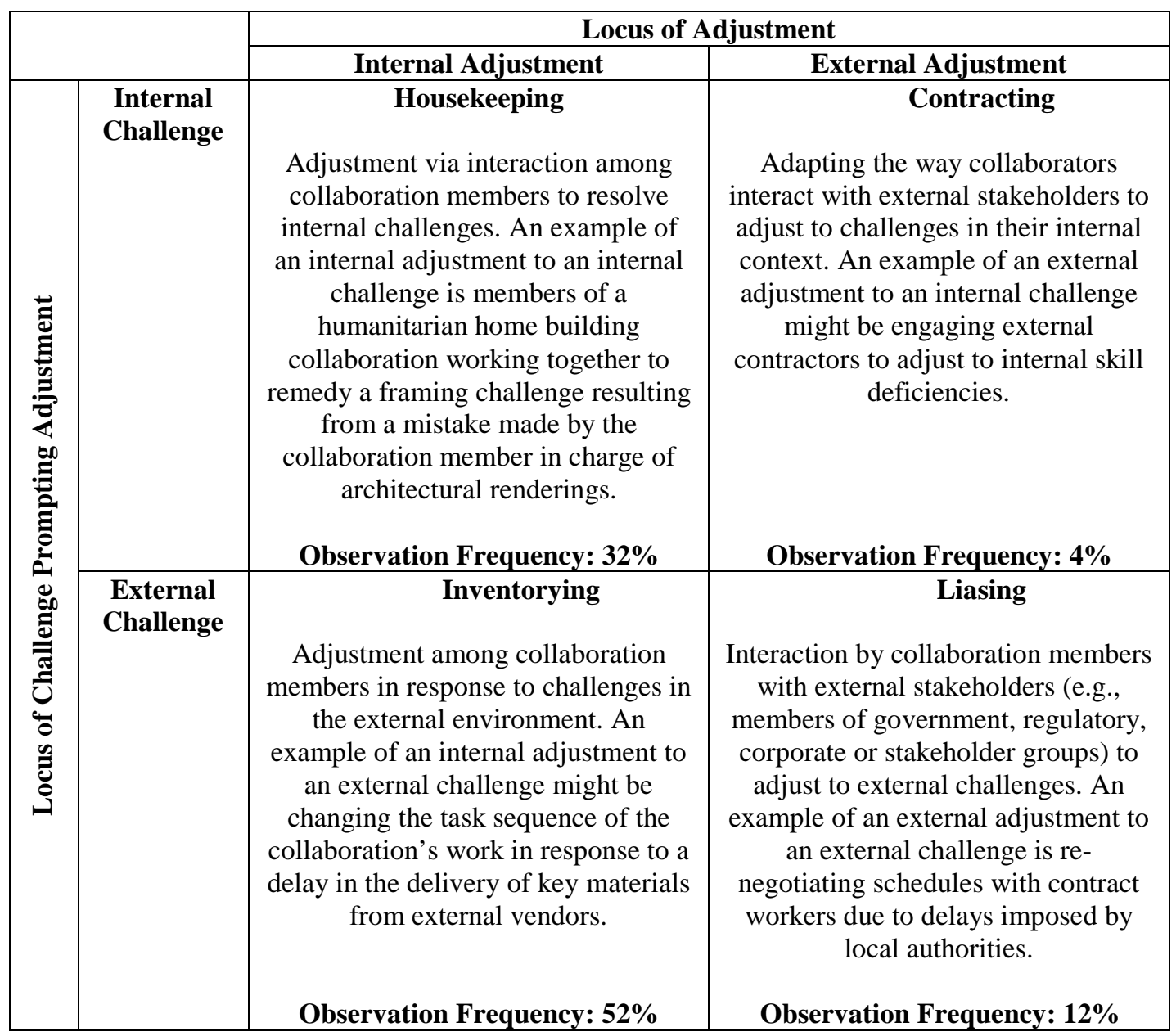


TABLE 3

Four Approaches to Adjustment

\begin{tabular}{|l|c|c|}
\hline \multicolumn{1}{|c|}{ Type of Adjustment } & $\begin{array}{c}\text { Count of } \\
\text { Observations }\end{array}$ & $\begin{array}{c}\text { Percentage of } \\
\text { Observations }\end{array}$ \\
\hline Retreating & 23 & $12 \%$ \\
\hline Resolving & 136 & $73 \%$ \\
\hline Reconfiguring & 27 & $14 \%$ \\
\hline $\begin{array}{l}\text { Re-structuring/Re- } \\
\text { strategizing }\end{array}$ & 1 & $1 \%$ \\
\hline TOTAL & 187 & $100 \%$ \\
\hline
\end{tabular}

Note: We only observed one instance of re-structuring/re-strategizing. However, several accounts of this adjustment strategy being enacted at a more macro level were recounted to us during informal interviews. 
TABLE 4

Illustrative Examples of High, Moderate and Poor Performing Collaborations

\begin{tabular}{|c|c|c|c|c|}
\hline Name & Features & Nature of Challenges Faced & Nature of Adjustments & $\begin{array}{c}\text { Performance } \\
\text { Assessment }\end{array}$ \\
\hline Innercity3 & $\begin{array}{l}\text { * USA } \\
\text { * Several consistent participants } \\
\text { * Moderate heterogeneity (culture, age, } \\
\text { background, etc.) } \\
\text { * Mid-stage build }\end{array}$ & $\begin{array}{l}\text { * Complex roof design } \\
\text { * Matching people to tasks that they can do } \\
\text { * Error made by today's volunteers } \\
\text { * Heat } \\
\text { * Late arrival of supplies } \\
\text { * Nature of work (e.g., hauling heavy materials) }\end{array}$ & $\begin{array}{l}\text { * Outsource roofing on other homes } \\
\text { * Re-assigning tasks } \\
\text { * Water break } \\
\text { * Adjusting work schedule } \\
\text { * Finding an ingenious way to work together to } \\
\text { move heavy materials without equipment }\end{array}$ & $\begin{array}{l}\text { Very High } \\
\text { (Highest) }\end{array}$ \\
\hline City2 & $\begin{array}{l}\text { * USA } \\
\text { * Some consistent participants } \\
\text { * People coming and going } \\
\text { * Low heterogeneity (mostly white middle } \\
\text { aged men on the site today) } \\
\text { * Mid-stage build }\end{array}$ & $\begin{array}{l}\text { * A recent theft } \\
\text { * Error made by today's volunteers } \\
\text { * Unskilled volunteers } \\
\text { * Nature of the work on scaffolding } \\
\text { * Need to work with people both on and off the } \\
\text { site today } \\
\text { * Balloon lost in pipe }\end{array}$ & $\begin{array}{l}\text { * Waiting to install expensive appliance until } \\
\text { house is enclosed } \\
\text { * Fixing error } \\
\text { * More skilled volunteers helping less } \\
\text { experienced ones } \\
\text { * Relying on volunteers on the group to help those } \\
\text { working on scaffolding } \\
\text { * Using technology to work with people on and } \\
\text { off the site }\end{array}$ & High \\
\hline $\begin{array}{c}\text { Latin } \\
\text { Outskirts }\end{array}$ & $\begin{array}{l}\text { * Costa Rica } \\
\text { * Moderately high heterogeneity (high } \\
\text { functional background heterogeneity, } \\
\text { moderate cultural heterogeneity, high age } \\
\text { heterogeneity, high gender heterogeneity) } \\
\text { * Closed brigade consisting of individuals } \\
\text { from the USA } \\
\text { * Early stage build }\end{array}$ & $\begin{array}{l}\text { * Lack of tools to use } \\
\text { * Lack of construction expertise/leadership on site } \\
\text { * Heat } \\
\text { * Problem getting funds to contractor to purchase } \\
\text { materials for the homes } \\
\text { * One leader not on the site this week (shortage of } \\
\text { leadership from home building organization) } \\
\text { * Heat } \\
\text { * Cultural conflict (expectation that family would } \\
\text { help, but culturally taboo for women to work } \\
\text { construction in CR) } \\
\text { * Insects } \\
\text { * Rain } \\
\text { * Language barrier between contractor (with } \\
\text { construction expertise) and volunteers } \\
\text { * Challenging nature of the work } \\
\text { * Difficulty getting recipient family to be on site } \\
\text { * Error by collaboration due to lack of expertise } \\
\text { * Dispute by group members on how to proceed } \\
\text { * Water from the neighbors' laundry on the } \\
\text { building site } \\
\text { * Request for many changes to the home/special } \\
\text { features by home recipients }\end{array}$ & $\begin{array}{l}\text { * Volunteers purchased tools } \\
\text { * Waiting for help to arrive } \\
\text { * Changing the way the group worked together } \\
\text { (e.g., local collaboration leader filling in as lead } \\
\text { for regular local leader, and brigade members } \\
\text { taking more initiative and problem solving } \\
\text { * Local collaboration leader negotiated with } \\
\text { contracted foreman and expressed concern that he } \\
\text { be on site } \\
\text { * Local collaboration leader leaving brigade to } \\
\text { work out problem with transfer of funds } \\
\text { * Changing work schedule to accommodate heat } \\
\text { * Use of translator for volunteers to communicate } \\
\text { with construction lead } \\
\text { * Outsourced some of the digging } \\
\text { * Fixing error } \\
\text { * Asking for a bucket to bail neighbors' laundry } \\
\text { water out of the septic tank hole they were digging } \\
\text { * Trying to accommodate requests of home } \\
\text { recipients }\end{array}$ & $\begin{array}{l}\text { Very Low } \\
\text { (Lowest) }\end{array}$ \\
\hline
\end{tabular}




\begin{tabular}{|c|c|c|c|c|}
\hline Name & Features & Nature of Challenges Faced & Nature of Adjustments & $\begin{array}{c}\text { Performance } \\
\text { Assessment }\end{array}$ \\
\hline Coastal1 & $\begin{array}{l}\text { * USA } \\
\text { * One formal leader and one informal leader } \\
\text { (who appears to take the lead)—-these are the } \\
\text { only } 2 \text { workers from the home building } \\
\text { association on site_-the rest are contract } \\
\text { workers \& volunteers } \\
\text { * No formal start; no formal instructions } \\
\text { * Moderately high heterogeneity (high } \\
\text { gender heterogeneity, high age heterogeneity, } \\
\text { moderate culture heterogeneity, probably } \\
\text { fairly high background heterogeneity) } \\
\text { * Some regular volunteers on site } \\
\text { * Projects assigned to some sub-groups and } \\
\text { some individual workers } \\
\text { * A less cohesive group today than others } \\
\text { observed } \\
\text { * Workers appear to be fairly self-directed } \\
\text { * Mid-stage build }\end{array}$ & $\begin{array}{l}\text { * Fire department shut down their work on one of } \\
\text { the homes for fire code non-compliance } \\
\text { * Solar panels are late and haven't been delivered } \\
\text { yet } \\
\text { * Cold weather } \\
\text { * Errors made by previous collaboration } \\
\text { * Difficulty of work due to design of house } \\
\text { * Mutually exclusive tasks to be performed } \\
\text { * Error made by individual on this collaboration } \\
\text { * Challenges posed by overhead wiring on site } \\
\text { * Volunteer(s) hard of hearing }\end{array}$ & $\begin{array}{l}\text { * Waiting on building some of the homes- } \\
\text { rearranging the order of construction tasks and } \\
\text { waiting to tile roofs (re-arranging sequence of } \\
\text { tasks to be performed) } \\
\text { * Involving contract workers earlier than } \\
\text { originally anticipated } \\
\text { * Fixing errors of previous collaboration } \\
\text { * Re-arranging sub-tasks for today to work around } \\
\text { mutually exclusive tasks } \\
\text { * Using different tools (e.g., nail gun) to work in } \\
\text { tight or difficult spaces } \\
\text { * Contract worker adapting compacting process to } \\
\text { avoid overhead wires } \\
\text { * Adjusting way of speaking to volunteers that are } \\
\text { hard of hearing } \\
\text { * Breaks }\end{array}$ & Moderate \\
\hline Coastal2 & $\begin{array}{l}\text { * USA } \\
\text { * Group consisted of home building } \\
\text { association volunteer coordinator, site co- } \\
\text { lead, } 3 \text { Americorp members, regular } \\
\text { volunteers, and corporate volunteers } \\
\text { * Group divided into 2: those working up } \\
\text { high and those working on the ground } \\
\text { * Friendly collegial group; seemed to be a } \\
\text { sense of sub-group membership and pride } \\
\text { * Mid-stage build } \\
\text { * Moderately high heterogeneity (e.g., age, } \\
\text { culture, gender, functional background) }\end{array}$ & $\begin{array}{l}\text { * Cold } \\
\text { * Task of moving heavy materials } \\
\text { * Shortage of help from construction lead (to due } \\
\text { large number of people on the site today) } \\
\text { * Complaints from neighbors about construction } \\
\text { dust } \\
\text { * Not enough work-waiting for work to do } \\
\text { * Threat of rain } \\
\text { * As in other Coastal collaboration, what they can } \\
\text { do is still impacted by delay in arrival of solar } \\
\text { panels and instructions }\end{array}$ & $\begin{array}{l}\text { * Using backhoe to move heavy materials } \\
\text { * Waiting to talk with construction lead } \\
\text { * Will have to water down site to keep the dust } \\
\text { down } \\
\text { * Taking break } \\
\text { * Preventative adjustment of sandbagging and } \\
\text { covering wood to protect the site from impending } \\
\text { rainstorm } \\
\text { * Waiting to tile the roof (re-arrangement of } \\
\text { sequence of tasks) due to delay in arrival of solar } \\
\text { panels }\end{array}$ & Very High \\
\hline Rainforest & $\begin{array}{l}\text { * Costa Rica } \\
\text { * Homes in all stages } \\
\text { * High heterogeneity (gender, age, functional } \\
\text { background, language, culture) } \\
\text { * Group consists of } 6-10 \text { workers from the } \\
\text { home building association, about } 22 \text { brigade } \\
\text { members, contract workers, local volunteers, } \\
\text { and professionals from capital city invited to } \\
\text { participate as volunteers, and home recipients } \\
\text { * Identification with sub-groups }\end{array}$ & $\begin{array}{l}\text { * Rain and mud } \\
\text { * Not enough work } \\
\text { * Language barriers } \\
\text { * Cultural challenge of Americans wanting to } \\
\text { work faster than was safe in the rain } \\
\text { * Inadequate tool to paint with } \\
\text { * Volunteer mistakes } \\
\text { * Difficulty agreeing on process } \\
\text { * Challenge of knowing things can be done better } \\
\text { * Broken bus } \\
\text { * Noise on the site (communication challenges) } \\
\text { * Arrival of new members } \\
\text { * Delayed lunch } \\
\text { * Cultural misunderstanding regarding lunch time }\end{array}$ & $\begin{array}{l}\text { * Putting rocks on the path to make it easier to } \\
\text { transport materials } \\
\text { * Taking mud out of houses; adjusting sequence } \\
\text { of work processes } \\
\text { * Taking rest breaks } \\
\text { * Using translators and hand motions } \\
\text { * Needing to adapt pace of work—-slow down } \\
\text { * Compromise } \\
\text { * Just doing what they're told to do } \\
\text { * Taking people to the site in } 2 \text { shifts } \\
\text { * Integration of new collaboration members } \\
\text { * Re-arranging events while waiting on lunch } \\
\text { * Ending day early } \\
\text { * Apologies by Costa Ricans for lunch delay }\end{array}$ & Moderate \\
\hline
\end{tabular}


